\title{
Audit Sampling - statistical vs. non-statistical?
}

\author{
Boris Mucha, Patrícia Brestovanská and Tomáš Peráček \\ Faculty of Management, Comenius University in Bratislava, Bratislava, Slovak Republic
}

\begin{abstract}
Correspondence should be addressed to: Boris Mucha; boris.mucha@fm.uniba.sk
Received date: 2 March 2018; Accepted date: 21 August 2018; Published date: 28 November 2018

Academic Editor: Diana Dumitrescu

Copyright (C 2018. Boris Mucha, Patrícia Brestovanská and Tomáš Peráček. Distributed under Creative Commons CC-BY 4.0
\end{abstract}

\begin{abstract}
In order to meet the objectives of the financial audit, it is necessary for auditors to state that the financial statements prepared by the management provide a true and fair view of the financial condition of the enterprise. With regard to the natural limitations of auditing, the auditor obtains reasonable assurance by generally verifying the selected sample of items from the population and passing the results of that verification to the entire population. The subject of this article is to select a sample in a financial audit. The authors point out the importance of the correct course of the auditor to ensure that the selected sample is objective, unbiased and representative in relation to the overall set of items. In addition to a comprehensive view of sample selection, the authors focus in particular on analyzing and comparing the statistical and non-statistical sampling method. The authors explain the fundamental differences between them which consist mainly of the degree of randomness and the use of probability theory to evaluate the results of the sample. They describe individual methods, possibilities and ways of their application. Last but not least, they warn the reader of the limitations and limitations associated with the use of particular methods in practice. Based on this research, as well as on the basis of their own practical experience with the performance of the audits, the authors endorsed their own recommendations, the application of which will contribute to the increase of the quality of the financial audits carried out.
\end{abstract}

Keywords: audit, sample, risk, stratification

Cite this Article as: Boris Mucha, Patrícia Brestovanská and Tomáš Peráček (2018)," Audit Sampling statistical vs. non-statistical?" Journal of Eastern Europe Research in Business and Economics, Vol. 2018 (2018), Article ID 136905, DOI: 10.5171/2018.136905 


\section{Introduction}

Increasing confidence is one of the primary goals of auditing financial statements. To achieve this goal, it is essential that the auditor finds that the financial statements prepared by the management are consistent with the applicable financial reporting framework and that these statements provide a true and fair view of the company's financial condition.

Audited financial statements are all statements of the business entity which this entity creates (Ölvecká, 2014). International auditing standards require auditors to obtain reasonable assurance that the audited financial statements are free from misstatement, mistakes or fraud during the audit. This should also be supported by the European Union's efforts on the consistency and comparability of standards in accounting, by adopting IFRS 9 (Ringsdorf and Kajanová, 2016). Adequate reassurance means a high degree of assurance that the auditor obtains by acquiring sufficient and appropriate audit evidence to reduce the audit risk to an acceptably low level. However, a reasonable assurance does not represent an absolute level of assurance because the audit has natural limitations, resulting in auditor's evidence on the basis of which the auditor concludes and bases his opinion, mostly compelling rather than convincing (ISA 200, 2009).

The auditor shall base his opinion on the audit evidence which must be appropriate and sufficient. Suitability testifies the quality of the evidence, their validity and reliability in relation to the audit objectives. Sufficiency is a quantitative parameter that influences the level of risk of misstatement. And just the sufficiency parameter is directly related to verifying the selected sample of items from the population and passing the conclusions of this verification to the entire population.

\section{Objectives of the Paper and Methodology}

The main objective of this paper is to analyse sample selection as one of the auditor's partial tasks in the conduct of a financial audit and to demonstrate the importance of the auditor's good practice in choosing an objective, unbiased and representative sample in relation to the total set of items.

The partial goals are:

- confirm or reject the hypothesis that the sample selected by the statistical methods is more objective and representative in relation to the total population compared to the sample selected by non-statistical methods;

- analyse individual statistical and non-statistical methods of sampling, the advantages and disadvantages of their use in practice;

- define factors that affect the sample size.

The following scientific methods were used in the research: analysis, synthesis, description, comparison. Through the analysis of audit procedures from international auditing standards as well as our own experience in practice, we identified the benefits and risks associated with the sampling of the financial audit. Finally, we have also used the knowledge of other domestic or foreign researchers who are concerned with the issue such as Kareš, Králiček, Müller and others. 


\section{Results}

From a theoretical point of view, the ideal status is to verify all items (one hundred percent review) by which the auditor obtains an absolute level of assurance. Today, by some special tools, it is possible to test 100 percent of the records included in a file; this is a marked improvement over the sampling techniques historically found in the traditional manual audit (Byrnes, Benita, Brown-Liburd et al., 2012). In practice, this method is used in the detailed test and its use is suitable, for example:

- when verifying a small number of items that are generally of high value,

- when there is a high risk if adequate and sufficient audit evidence cannot be obtained; or

- when testing is performed automatically by the information system and the $100 \%$ review is cost-effective (ISA 500, 2009).

In our opinion, however, in most cases, this method is unrealistic for the high number of all items in given population, hundreds or thousands of credit or debit transactions on bank accounts, and so on. For this reason, auditors are required to obtain "at least" reasonable assurance that they acquire by verifying part of the items -verifying the sample.

Items can be selected by the auditor through two methods, namely; by selecting specific items or by selecting the sample to be audited. In deciding whether to use the above methods, the auditor should base their judgment on professional opinion and consider the specific circumstances, in particular; the effectiveness of the method chosen to assess the degree of risk or the cost effectiveness of the audit.
Selection of specific items is appropriate to use in cases where certain items have specific properties within a file. The auditor should use this method to derive from the knowledge of the business entity's specifics. Specific items for selecting specific items method are, for example, items with a high unit price, high abundance, key items, or items that represent a significant part of the verified area. Key items can also be items that are suspicious, unusual, extremely vulnerable to the risk or mistaken in the past (ISA $500,2009)$.

We emphasize that there is no universal key to assess these facts, and the auditor must rely on their knowledge and experience. Selection of specific items is useful for the testing of substantive testing and as well as auditing of the business entity or confirmation of the risk assessment by the auditor. Although it is an effective means of collecting audit evidence, it is not a selection of the sample being tested because the results cannot be transferred to the complete total set. However, it can be useful in an auditing approach that provides a reasonable guarantee without sampling (European Court of Auditors, 2012).

Sampling in the true sense of the word is only a selection of the sample being tested. Its purpose is to design and select a sample in a predetermined manner, carry out verification by means of audit procedures on the items in this sample, and evaluate the results of the sample verification so as to provide a suitable basis for drawing conclusions in relation to the whole sample file.

Each sample unit within the population should be allowed to be sampled. Compliance with this rule is a necessary basis for creating an objective, unbiased and representative sample of the overall set (Kareš, 2014). However, it is not excluded that the sample size will need to be adjusted during testing, depending on

Boris Mucha, Patrícia Brestovanská and Tomáš Peráček (2018), Journal of Eastern Europe Research in Business and Economics, DOI:10.5171/2018.136905 
the level of materiality and the required reliability.

\section{Sampling Risk}

The size of the sample selected should be sufficient to allow the auditor to conclude that the deviation rate in the control tests exceeds the acceptable deviation rate that the auditor is willing to accept and that the cash amount of the deviation in the substantive accuracy test for the details does not exceed the amount that the auditor is willing to accept (Felix, 1978). In this context, we are talking about sampling risk; the essence of which is that the conclusion of the sample-based auditor may be different from the conclusion the auditor would have reached if he audited the entire population by the same audit procedure (Hitzig, 1995). The risk of sampling can lead to two types of incorrect conclusions, namely:

- In the control tests, controls will be more effective than they are or in the tests of details there will be no significant misstatements, although they exist or vice versa

- In control tests, controls will be less effective than they are or in the tests of details there will be significant misstatements, although they do not actually exist.

The risk referred to in point 1 increases the probability of inaccurate or incorrect opinion of the auditor and thus affects the effectiveness of the audit; the risk described in point 2 often leads to further work that must confirm or rebut that the initial conclusions were incorrect, which has a negative impact on the time and cost effectiveness of the financial audit performed. For these reasons, it is entirely natural that the auditor is concerned about inaccurate or even imprecise conclusions if they are testing only the selected sample because this risk affects the effectiveness and efficiency of the audit and increases the probability of the auditor's inappropriate opinion.It is necessary to distinguish between sampling risk and non-sampling risk. Such a risk may be, for example, the misinterpretation of audit evidence, the use of inappropriate practices or other human factor failure.

\section{Sample Definition}

Verification accuracy is directly related to the probability that the sample selected from the total file will represent the total population of items. The larger the sample we choose, the higher the accuracy of the verification and the lower the risk of deviations. In addition to sample sizes, other procedures are also available to increase verification accuracy, testing high value items, testing key items, and more (Epstein and Mirza, 2003).

Before the auditor proceeds to the sampling process itself, they must answer a number of basic questions concerning the total sample file and the application of the sample verification results to the total set of items (Picture 1). 


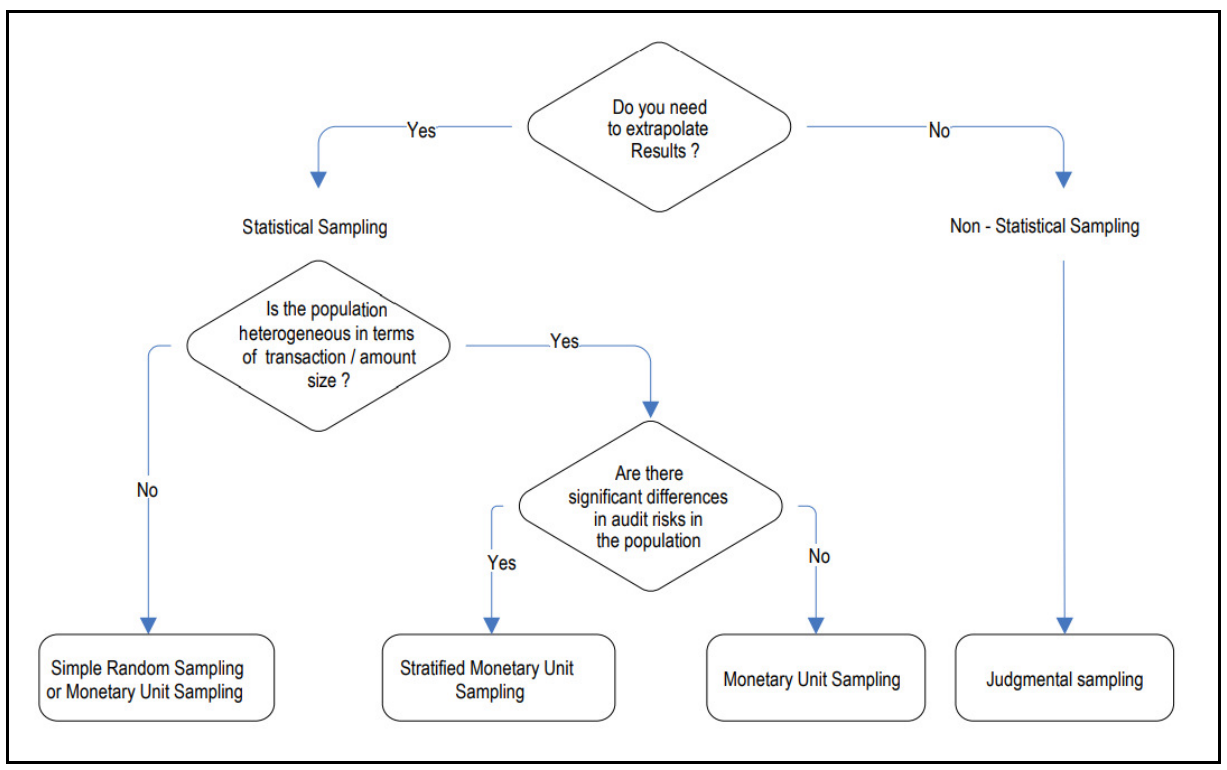

Figure 1: (resource: European Court of Auditors. 2012. Financial and Compliance Audit Manual)

The sampling procedure involves several preparatory steps that the auditor must take to select the appropriate sample, namely:

1. Define what constitutes an error depending on the type of audit performed; whether it is a compliance audit or a financial audit. The auditor must evaluate the expected amount of errors, respectively; expected error rate.

2. Specify the total file that means to define the complete set of data from which the items will be selected in the sample. Such a file can be, for example, all non-cash transactions, record of receivables, etc.

3. Explore the nature of the whole file, both individually and in context. On the basis of the information obtained, the auditor may then choose the appropriate sampling method as well as the optimum sample size.
4. Prepare the total population from which the sample will be taken. At the same time, the auditor must consider whether the sample is too heterogeneous, and in this case consider redistributing it to several subsamples with the same or similar characteristics; the verification of which the specific audit objectives will be better achieved. This method is called stratification (see below).

5. Stratify the sample (if appropriate).

6. Specify sample size. For the purpose of selecting a statistical sample, it may be advisable to select a sample of a minimum of 30 items from each total set or sub-file, if the auditor stratified the population. For a file or subset containing less than 30 items, we recommend a $100 \%$ review.

7. Select the sample selection method. The selected method 
must match the characteristic features of the overall set. Based on the focus and objective of the audit, as well as its professional judgment, the auditor will decide on the statistical or nonstatistical method of sampling, as well as on a specific method.

\section{Stratification}

As noted above, stratification means splitting the total file into sub-groups or layers using predefined and documented audit criteria, so that the sampling unit can only belong to one and the same subset and applying auditing techniques to sample items from all sub-files (European Court of Auditors, 2012). Its aim is to increase the effectiveness of the audit by reducing the diversity of items by dividing the total population into subpopulations. The sample size can be reduced without increasing the risk of sampling.

The criterion may be, for example, monetary value, age of receivables, etc. For example, due to stratification, the auditor may focus on items with a higher monetary value; which have a higher risk of overvaluation. Payments may also be stratified for subpopulations, in order to place greater emphasis on risk-priced interim and final payments, and advances that are less prone to risk.

From the point of view of the possibility to pass the results of the item's sample verification to the total file, we note that such conclusions can only be made in relation to the particular layer (sub-file) from which the partial sample was selected. For example, if they are subject to bank transaction verification and $20 \%$ of these transactions represent $90 \%$ of the monetary value of the cleared funds, the auditor examines a sample selected from only those $20 \%$ of the transactions. After evaluating the results of this sample, it concludes with conclusions that concern only $90 \%$ of the monetary value. These conclusions cannot be transferred to other transactions that represent the remaining $10 \%$ of the value. In relation to them, they must select another sample to evaluate these $10 \%$ as insignificant.

\section{Factors Affecting Sample Size}

The size of the sample depends on the type and focus of the audit or test, on the sampling method, whether the auditor chooses for the statistical or nonstatistical sampling. However, there are several other factors that influence the auditor's decision. The impact of these factors may be positive or negative, which means that the auditor decides to increase or decrease the sample depending on the judgment.

According to Müllerová (2013), the factors that influence the increase of the sample are mainly:

- an increase in the required assurance that the actual misstatement in the population is not higher than the permissible misstatement,

- an increase in the amount of misstatement the auditor expects in the population,

- an increase in the auditor stated risk of material misstatement,

- an increase in the expected rate of variation in the population tested.

In such cases, the auditor needs to increase the sample in order to make a better and more accurate picture of the overall population or to better estimate the true value of deviations and misstatements in the overall population. Under certain circumstances, the auditor may decide that for some of the controls or tests is acceptable a different degree of deviations and misstatements. 
In addition to increasing the permissible error rate or the increase in permissible misstatement, the stratification factor is also a factor influencing the reduction of the sample. If the auditor divides the population into layers, the subsets, as a rule, the sum of items in individual subpopulations is smaller than the number of a single sample selected from the total file.

\section{Sampling Methods}

The auditor may decide to select the sample in a statistical or non-statistical way. The characteristic features of random sample selection are the random selection of items and the use of probability theory to evaluate the results of the sample (Müllerová and Králiček, 2014). If the method used by the auditor does not indicate these two features, we are talking about unsatisfactory sampling.

In addition to the method of selecting items, there is a significant difference between the statistical and non-statistical selection and the possibility of applying the sample test results to the total set. The results of sample testing can only be transferred to the entire population if the statistical choice has been used (Kareš and Máziková, 2014), so only the sampling method is used for Déclaration d'assurance (DAS). Conversely, nonstatistical sampling is used for indicative purposes only.

Based on our practical experience, we know that, in addition to objective facts, the professional judgment of the auditor plays an important role in the decisionmaking process, which is necessary not only at the sampling phase but also throughout the whole audit process. The education and the auditor's experience are essential for assessing all audit risks, correctly determining the scope of the audit, timing, and assessing the evidence and drawing conclusions (Saxunová,
2017). Hand in hand with the auditor's professional judgment, their professional scepticism must also go through, which involves not only a critical view of assessing audit evidence, but constantly considering and questioning the reliability of information.

If the auditor decides, we recommend using a statistical choice, especially for populations with number of items greater than 50. In the case of smaller populations, we advise to investigate the population in its entirety and to use nonstatistical methods only if, for objective reasons, such a review is impossible or ineffective.

If the auditor decides on the statistical method of sampling, they have the choice between the following methods:

a) random selection,

b) the systematic selection,

c) monetary unit sampling.

Random selection works with randomness as a statistical phenomenon. Using this method, the principle is that each population unit has the same chance of getting into the sample. The basic advantage is the elimination of undesirable phenomena. Random selection is, in practice, carried out most frequently through a generator of random numbers or via a random number table, in MS Office - Excel, however, it does not exclude draw. Unfortunately, even with the use of this method, the risk of negative sampling effects, such as repeated draws when selecting an "undesired" item, and so on, cannot be totally excluded.

Systematic selection works with a selection interval, which is calculated as the share of the number of population items and the sample size to be selected, e.g. if the population has a total of 800 items and the sample should contain 50 
items, then each sixth item $(800 / 50)$ is selected from the population, it means item no. 1 , no. 17 , no. 33 , no. 49 , etc. A randomized population is a prerequisite for objective selection. Increased randomness can be achieved by choosing the starting point randomly, ideally by a random number generator or a random number table.

Sample collection by monetary unit sampling (MUS) is the last of the statistical methods used to choose the audit sample. It is based on the principle that each euro has the same possibility to be selected. MUS is the form of sampling based on the possibility of the corresponding size. Larger transactions involve paying higher amounts in euros, representing a larger share of potential "hit euros", so they are more likely to be tested in a sample (European Court of Auditors, 2012). MUS is a type of a valueweighted selection.

If the auditor chooses a non-statistical selection, he should try to approach the sample objectively and unbiased; as there is no rule that each item in the population has the same chance of being selected into the sample. Among the non-statistical methods of selecting patterns, we find:

a) haphazard selection method,

b) block selection.

If the auditor chooses the haphazard selection method, no predetermined technique is retained. In this case, we emphasize the need to avoid bias or predictability; in the form of selecting the first and last items on either side or excluding them from the selection, and so on (ISA 530, 2009). In this context, we note that this method does not usually work due to the selective bias of the auditor for whom unrepresentative samples are knowingly or unknowingly formed.
Block selection, respectively group selection, is a selection of several consecutive items from the population, it means selection of block or blocks. The use of this method in practice cannot be recommended in most cases because the following items often have similar features but differ from other items in the population, so the auditor cannot reach a conclusion that is valid for the entire population. Therefore, we recommend that this method can be used only after careful consideration following a previous assessment of the entire population and to select large number of small blocks to use it in order to increase the representativeness of the sample.

\section{Conclusion}

One of the overall objectives of an independent auditor is to correctly apply the audit procedures and obtain sufficient and appropriate audit evidence from which the auditor can draw reasonable conclusions and base their expert opinion. Due to the amount of financial statements and supporting documentation, it is not generally possible to carry out a $100 \%$ examination and testing of all items and therefore the auditor must choose and select a sample that will represent the overall data set.

Sample collection involves higher risk of deviations or inaccuracies, and the auditor can reach a conclusion other than that they would have reached in the verification of the sample if he verified the entire population by the same procedure. Therefore, the choice of an unbiased, objective and representative sample is crucial. The auditor should be careful to properly assess the level of risk, the expected and permissible error rate, and so on.

More important than the sampling process itself, is all the preparatory nature of the sample that precedes the

Boris Mucha, Patrícia Brestovanská and Tomáš Peráček (2018), Journal of Eastern Europe Research in Business and Economics, DOI:10.5171/2018.136905 
selection of the sample. The auditor must correctly determine the entire set of items, examine it and prepare for selection. At the same time, negative external influences should be avoided. If appropriate or even necessary, the sample should be stratified, divided into multiple layers with items with the same or similar features.

The use of a statistical or non-statistical method of sampling shall be decided by the auditor based on the assessment of individual items and the total population. Following the results of our analysis, the auditor may generally recommend the use of statistical sampling methods, precisely because of their demonstrably higher objectivity from randomness as a statistical phenomenon. The correctness of the hypothesis that the sample selected by statistical methods is more objective and representative in relation to the total population as compared to the sample selected by non-statistical methods was also confirmed by the conclusion that the results of sample testing are not permissible to be transferred to the total population if non-statistical methods are used. We recommend using it only for populations with a number of items of less than 50, even if for objective reasons, it is not possible to verify all items in the population. Disadvantage of the use of non-statistical methods is the higher demands placed on the auditor's expertise and the lack of interest of the auditor and the associated selection risk also arise.

Finally, we can say that, in addition to objective facts, the auditor should rely heavily on their professional opinion, which includes not only the knowledge but also the practical experience required to conduct the audit properly.

\section{Acknowledgment}

The contribution was written within the research project VEGA $1 / 0218 / 16$ on „The Model of the implementation of controlling as a management tool within medium enterprises in the engineering and electronics industries".

\section{References}

- Byrnes, P., E., Benita, G., Brown-Liburd, H. et al. (2012).Evolution of Auditing: From the Traditional Approach to the Future Audit. AICPA, Durham.

- European Court of Auditors. (2012). Financial and Compliance Audit Manual. European Court of Auditors, Luxembourg.

- Epstein, B., J. and Mirza, A., A. (2003). Interpretation and Application of International Accouting Standards. John Willey and Sohns, New York.

- Felix, W., L. (1978). Sampling Risk vs. Nonsampling Risk in the Auditor's Logic process. University of Kansas. Kansas.

- Hitzig, N. B. (1995). Audit Sampling: A Survey of Current Practice. The CPA Journal, 65 (7).

- Kareš, L. (2014). Audítorské postupy. Wolters Kluwer, Bratislava.

- Kareš, L. and Máziková, K. (2014). Štatistické metódy $\mathrm{v}$ audite. Wolters Kluwer, Bratislava.

- International Standard on Auditing 200 (ISA 200). (2009) Overall Objectives of the Independent Auditor and the Conduct of an Audit in Accordance with International Standard on Auditing. 
- International Standard on Auditing 500 (ISA 500). (2009). Audit Evidence.

- International Standard on Auditing 530 (ISA 530). (2009). Audit Sampling.

- Müllerová, L. (2013). Auditing pre manažérov, Wolters Kluwer, Bratislava.

- Müllerová, L. and Králiček, V. (2014). Auditing. Oeconomica, Praha.

- Ölvecká, V. (2014). Medzinárodné štandardy pre finančné výkazníctvo, Proceedings of Obchod a finance 2014:
Mezinárodní vědecká konference Praha, 15 May 2014. Prague. Czech Republic, ISBN 978-80-213-2474-9, 24-29.

- Ringsdorf, B. and Kajanová, J. (2016). International Financial Reporting Standards and The Need of Hedge Accounting, Wolters Kluwer, Bratislava.

- Saxunová, D. (2017). Accountant and auditor and their skills and competences in contemporary environment, Sociálno-ekonomická revue, 15(2), 43-47. 